\title{
Dilemas sobre o fim-da-vida: informações sobre a prática médica nas UTIs
}

\author{
Dilemmas of the end-of-life: \\ information about the medical practice in the ICUs
}

Debora Gaudencio ${ }^{1}$

O ctavio M esseder ${ }^{2}$
${ }^{1}$ Hospital Português da Bahia. Av. Princesa Leopoldina 914/101, Barra Avenida. 40140-005

Salvador BA.

debora gaudencio@

yahoo.com.br

${ }^{2}$ Departamento de

M edicina, Faculdadede

Medicina da Bahia, UFBA.
Abstract The objective of this research was to investigate the knowledge, opinion and practice of critical care physician concerning end-of-life decisions. In this descriptive and cross-sectional study a questionnaire was applied to the physicians working in Intensive Care Unit (ICU) or Semi-ICU of 5 H ospitals in Salvador, Bahia State. Currently the physicians dealing with terminal patients are indeed concerned about providing comfort to their patients, and at times even avoiding the use of life support measures. N evertheless, many of the participants admitted that they have omitted information regarding these decisions in the medical records, as they fear consequences with the M edical Council or civil actions against them. This insecurity is related to the lack of information and the absence of an established and clear legislation on these matters. M ore discussions on this important subject are necessary, involving physicians, hospitals and patients.

Key words Dilemmas, End-of-life, Terminal patient, Decisions, Life support measures
Resumo 0 objetivo desta pesquisa foi coletar informações acerca do conhecimento, opinião econduta dos médicos intensivistas sobre questões a respeito das decisões em pacientesterminais. $N$ este estudo descritivo, de corte transversal, foi aplicado um questionário aos médicos que trabalham em UTIs e semi-UTIs de cinco hospitais em Salvador (BA). Pode-se perceber que existe uma tendência dos médicos que lidam com pacientes terminais a assumir condutas para fornecer conforto, deixando inclusive de introduzir um mecanismo de suporte de vida (M SV). Entretanto, a maioria dos participantes admitiu que omite informações no prontuário por receio de punições pelo código de ética e/ou código penal. Essa insegurança podeser relacionada com a falta deinformação por parte dos profissionais, bem como a ausência de uma legislação clara e objetiva sobre 0 assunto. Portanto, amplas discussões multidisciplinares acerca dessas questões fazem-se necessárias no ambiente hospitalar.

Palavras-chave Dilemas, Fim-de-vida, Paciente terminal, Decisões, M ecanismos desuportedevida 


\section{Introdução}

A morte está longe de ser um tema de fácil abordagem e manejo ${ }^{1}$. Dentre as questões evocadas está o processo de morrer, completamente imbricado em aspectos como sofrimento e qualidade do fim-da-vida ${ }^{2}$. Logo, debates sobrea conduta diante de pacientes terminais, como a eutanásia ea distanásia, tornam- se inevitáveis, o que parece exigir a compreensão do fenômeno próprio representado pela morte, para uma delimitação mais adequada do problema, tanto em termos individuais, quanto coletivos ${ }^{3}$.

0 progresso da medicina e a adoção de terapias extraordinárias de suporte de vida dificultam a definição dos limites terapêuticos nos cuidados intensivos e podem não respeitar os princípios éticos da beneficência e da não maleficência. Apesar de atitudes de limitação terapêutica naUTI diantede pacientes sem esperança de vida já ocorrerem de acordo com conceitos éticos e morais defensáveis, muitas vezes são acompanhadas de grandes conflitos bioéticos, entre os integrantes das equipes assistenciais efamiliares ${ }^{4}$.

Quando a concepção da família a respeito da situação clínica do paciente difere significativamente em relação a do médico, torna-se improvável alcançar um plano de tratamento apropriado. N esses casos, o médico deve esclarecer sobre sua posição e concordar em encontrar-se novamente com a família após consultar outros profissionais, comitêde ética da instituição na qual o paciente se encontra e pesquisar sobre outros recursos terapêuticos ${ }^{5}$. M as a quem deveria estar centralizado o poder decisório? Não deveria 0 próprio paciente decidir, se apresentar condições clínicas, sobre seu processo de morrer?

0 avanço tecnológico tornou possível manter viva uma pessoa muito doente ou em estágio terminal, porém ligada a aparelhos de sustentação artificial da vida, como a ventilação mecânica. Esses recursos terapêuticos podem ser considerados indispensáveis e heróicos em um caso e desnecessários em outro ${ }^{6}$.

Atualmente, as unidades de terapia intensiva recebem muitos enfermos portadores de doenças crônicasincuráveis, cujasintercorrências clínicas, as mais diversas, acabam sendo contempladas com os mesmos cuidados oferecidos aos doentes agudos. Se para a maioria dos pacientes pode-se alcançar plena recuperação, para os enfermos incuráveis pouco se oferece al ém de uma sobrevida precária e, às vezes, não mais que vegetativa. 0 orgulho de al cançar a cura facilmente setransforma em uma meta a ser atingida pel os médicos ea morte, em vez de ser vista como o desfecho natural da vida, passa a ser um inimigo a ser vencido?

Talvez o fato dos médicos se concentrarem apenas nos equipamentos, pulso, pressão sanguínea, secreções e excreções, esquecendo de enxergar o ser humano através do rosto amargurado pelo sofrimento, seja a tentativa de rejeitar a morte tão próxima que comprova a sua falta de onipotência e própria mortalidade ${ }^{8}$.

Alguns estudos já apontam que os cuidados médicos com o pacienteterminal envolvem, muitas vezes, o uso excessivo e inapropriado da tecnologia. Não são encontradas estatísticas precisas; todavia, pressupõe-se que milhares de doentes estejam internados em unidades de terapia intensiva sendo submetidos à prática médica fútil - ação médica cujos potenciais ben efícios para o paciente são nulos ou mínimos, não superando os seus potenciais malefícios. É importante mencionar que este conceito de futilidade gerou muitas controvérsias, já quea definição seria crucial nas decisões de não introduzir ou interromper intervenções 9 .

$\mathrm{NaEuropa}$, um estudo mostrou que $73 \%$ dos intensivistas admitem pacientes sem esperança de vida, sendo que $40 \%$ afirmam que, mesmo nesses pacientes sem prognóstico, o tratamento é feito com uso amplo de medicamentos e modalidades terapêuticas atéque morte seja concluída. Percebeu-se também que existem diferenças interessantes en tre o que os intensivistas fazem e 0 que eles acreditam que deveria ser feito ${ }^{10}$.

Os médicos intensivistas se deparam diariamente com questões como a introdução ea retirada de mecanismos de suporte de vida. Intensificando os dilemas, tanto dos profissionais da saúde quanto familiares e o próprio paciente assumem posições distintas diante das situações de pouca ou nenhuma esperança de vida.

Foi realizado um corte transversal e retrospectivo em que foram revisados todos os óbitos ocorridos em 2002 em três unidades de terapia intensiva pediátrica de referência de Porto Alegre por uma equipe de pesquisadores treinados para esse fim. Foram avaliadas as características gerais, o modo de morte (ressuscitação cardiopulmonar, morte encefálica, ordem denão reanimar, não oferta eretirada de suporte vital), o tempo de internação, o plano de final de vida e a participação da família nessa decisão. Os pesquisadores concluíram que a ressuscitação cardiopulmonar ainda é oferecida em uma frequência maior do que a descrita nos países do hemisfério norte, enquanto que a limitação de suporte vital é real izada preferencialmente através da ordem de não 
reanimar. Esse estudo mostrou uma pequena participação da família e evidenciou dificuldades em relação às decisões de final-de-vida enfrentadas por intensivistas do sul do país ${ }^{11}$.

No Brasil, ainda não existem protocolos hospitalares de não ressuscitação (NR) e essa prática já é adotada com certa frequência, apesar de não ser formalmente registrada em prontuário. Geralmente, as ordens de NR são dadas verbalmente e de maneira informal, com o intuito de "deixar o paciente morrer", no caso de sofrer parada cardiorrespiratória, na tentativa de evitar desgaste emocional do paciente e da família. Esta decisão, muitas vezes eticamente adequada por atender aos princípios da beneficência e não maleficência, pode infringir o princípio da autonomia se sua adoção for unilateral, sem a participação do paciente ${ }^{12}$.

Um estudo realizado em 1992 nos Estados Unidos comparou as respostas de um questionário, cujas questões eram relacionadas ao fimda-vida, respondido por médicos e pacientes. Foi observado que a maioria desses dois grupos entrevistados acreditava que o próprio paciente, se apresentasse condições, deveria ser o responsável pelo processo de decisões sobre o seu fim-devida. A maioria dos médicos também considerava que eles deveriam ajudar e orientar os pacientes nas decisões ${ }^{13}$.

$\mathrm{Na}$ abordagem aos pacientes terminais, condutas como a não introdução de medidas, bem como a interrupção de alguma intervenção já iniciada, devem ser cautelosamente analisadas. Um questionário aplicado a médicos nos Estados Unidos e Inglaterra demonstrou que aproximadamente $59 \%$ dos mesmos não consideram eticamente diferentes não iniciar e retirar uma medida estabelecida ${ }^{14}$.

Para alguns autores, os médicos devem enxergar que os pacientes que estão morrendo na UTI querem que seus sintomas sejam bem tratados, seus desejos sejam respeitados e que permaneçam rodeados pelos seus entes queridos ${ }^{15}$. Quando a morte é inevitável, existe concordância de que ela seja tranquila, sem dor ou desconforto para todos os pacientes ${ }^{16}$.

Todos os casos que implicam decisões de vida e de morte são muito difíceis, pois envolvem desafios clínicos e problemas éticos complexos. E é notável quea literatura vem abordando com mais frequência os dilemas que envolvem o fim-davida, mas não existe um consenso ou modelo de prática médica para permitir uma morte digna e talvez nunca venha a existir, já que essa é uma definição estritamenteindividual, ou seja, somente o próprio sujeito queestá vivenciando a experiência da mortepoderia defini-la como digna ou não.

A questão é: 0 que fazer quando todos os recursos terapêuticos se esgotam? Entubar, iniciar a ventilação mecânica, manter a função cardíaca artificialmentee prolongar ao máximo a vida, ou essa conduta estaria não apenas adiando a morte, mas aumentando o sofrimento do paciente e seus familiares? Qual a opinião dos médicos sobre essas questões?

Diantedessa realidaderepleta dedilemas quanto à conduta direcionada ao fim-de-vida dos pacientes, éimportantequeos médicosintensivistas estejam não apenas familiarizados, mas atualizadose seguros em relação a alguns conceitos, questões éticas e jurídicas que serão fundamentais no exercício da medicina intensiva.

0 objetivo desta pesquisa foi coletar informações sobre o conhecimento, opinião e conduta dos médicos intensi vistas sobre questões a respeito das decisões em pacientes terminais internados em unidades deterapia intensi va de Salvador (BA).

\section{Material e métodos}

Utilizando os unitermos na língua inglesa death, end-of-life, decision-making, ICU, ethic e euthanasya, foi pesquisado, no PubM ed, artigos pertinentes e selecionados os mais aplicáveis a este estudo, visando a uma revisão bibliográfica, que forneceu fundamentação teórica ao projeto sobre conceitos éticos a respeito da prática médica e do morrer dignamente.

Trata-se de um estudo descritivo, de corte transversal, constituído por análise quantitativa, baseado em pesquisa de campo, realizado através da aplicação de questionário no período de janeiro a abril de 2007.

A população do estudo foi composta pelos médicos das unidades deterapia intensiva esemiintensiva do Hospital Português da Bahia, Hospital Salvador, Hospital Santa Izabel, Hospital Espanhol eH ospital Aliança. Foi decidido incluir médicos de diferentes hospitais, não só para se obter maior número de opiniões, mas também para evitar que estas pudessem ter sido influenciadas por condutas mais específicas de determinada instituição.

Para ser incluído no estudo, o participante deveria ser médico, atuando em ambiente de medicina intensiva dos hospitais supracitados. Eram excluídos aqueles que se recusassem a responder o questionário. Houve apenas uma recusa. 
0 instrumento utilizado para a coleta foi um questionário autoaplicável, anônimo, composto de questões que visavam traçar os dados sociodemográficos da população-estudo, bem como colher informações sobre a prática médica e opiniões diantedeum pacienteterminal. As perguntas incluíram questões sobre introdução, não introdução e retirada dos mecanismos de suporte de vida, distanásia, ortotanásia, eutanásia e os fatores que influenciam nas decisões.

0 questionário foi entregue pessoalmente ao médico que deveria assinar um termo de consentimento livreeesclarecido caso concordasseem participar da pesquisa. Osquestionáriosanonimamente preenchidos foram guardados em uma urna, que somente foi aberta ao final da coleta, preservando assim 0 anonimato dos participantes.

Ao término da aplicação dos questionários, um banco de dados foi montado com todas as informações contidas em cada questionário para análise.

0 atual projeto foi submetido à aprovação pelos comitês de ética em pesquisa do Hospital Português da Bahia, H ospital Santa I zabel, H ospital Espanhol e pelo Conselho M édico do Hospital Aliança antes do início coleta dos dados em cada instituição. 0 Hospital Salvador, por não possuir um comitê de ética, aceitou a aprovação dada pelo Hospital Português. Os sujeitos somente foram incluídos no estudo caso concordassem voluntariamente em participar do mesmo, assinando o termo de consentimento livree esclarecido.

Foi utilizado o programa SPSS 12 para a formação de um banco de dados e análise estatística através de distribuição percentual edeterminação de médias, mínimas e máximas.Os dados coletados foram submetidos a uma análise de conteúdo, que, deacordo com $\mathrm{Gi}^{17}$, constitui uma técnica de investigação, através de descrição objetiva, sistemática equantitativa do conteúdo, cuja finalidade é a interpretação dos dados.

\section{Resultados}

Foram respondidos 161 questionários. A Tabela 1 mostra as características demográficas dos 161 médicos que participaram da pesquisa. A maioria dos participantes, somando $77 \%$, é do sexo masculino, 68,3\% são casadose $65,8 \%$ são católicos. A idademédia da população foi de 34,99 anos e a média de tempo de trabalho foi de 4,99 anos.

A respeito da frequência com queos médicos participam de discussões sobre a não introdu- ção de um tratamento ou mecanismo de suporte de vida (M SV), as variáveis não foram quantificadas, já que o objetivo era saber a frequência com que o médico se sente abordado por essas questões, se tratando, portanto, de uma questão subjetiva. A maioria, $68,9 \%$, respondeu que participa frequentemente dessas discussões e 89,4\% afirmam já ter optado por não introduzir M SV, como é demonstrado na Tabela 2.

Foi questionado também sobre os participantes desses debates. Primeiramenteera perguntado quem participa da discussão e, em seguida, quem os médicos consideram que deveriam participar. 0 percentual foi maior na segunda pergunta em todas as opções de participantes. A diferença mais significativa foi em relação à participação dos pacientes; $19,9 \%$ dos médicos afirmaram queos pacientes participam e 77,0\% (124 médicos) consideram que eles deveriam ajudar nas decisões (Gráfico 1).

A Tabela 3 demonstra os fatores que influenciam nas decisões. Os participantes deveriam enumerá-los de 1 a 5 por ordem de importância ( 1 = mais importante $/ 5=$ menos importante). Setenta e sete por cento dos médicos participantes consideram as condições clínicas do paciente como o fator que mais influencia na decisão de introduzir um M SV e 36 afirmam quea idadeéo fator que menos influencia. E a respeito da legalização da eutanásia no Brasil, 32,9\% dos médicos são a favor, 41,6 \% são contra e 25,5 \% não têm certeza.

Tabela 1. Características da população-estudo.

\begin{tabular}{lrr}
\hline \multicolumn{1}{c}{ Características } & \multicolumn{2}{c}{$\mathrm{n}=161$} \\
\hline Idade & $35(26-60)$ \\
Sexo & \multicolumn{2}{c}{} \\
$\quad$ M asculino & 37 & $77 \%$ \\
$\quad$ Feminino & $23 \%$ \\
Estado civil & 43 & $26,7 \%$ \\
$\quad$ Solteiro & 110 & $68,3 \%$ \\
Casado & 6 & $3,7 \%$ \\
Separado & 2 & $1,2 \%$ \\
Vive com companheiro(a) & - & - \\
$\quad$ Viúvo & & \\
Religião & 106 & $65,8 \%$ \\
$\quad$ Católica & 28 & $17,4 \%$ \\
$\quad$ Espírita & 2 & $1,2 \%$ \\
Evangélica & 3 & $1,8 \%$ \\
Outras & 19 & $11,8 \%$ \\
Sem religião & 3 & $1,8 \%$ \\
$\quad$ Ateu & & \\
\hline
\end{tabular}


A pergunta 6 questiona seo médico éa favor de continuar submetendo o paciente terminal a todo tratamento e tecnologia disponível; $73,9 \%$ dos médicos responderam quenão. Já a pergunta 7 era sobre interromper um tratamento em caso depaciente terminal, 67,1\% são a favor. E a pergunta 8 indagava a respeito da retirada de um M SV; $50,3 \%$ se consideram a favor dessa conduta em casos de pacientes sem prognóstico (Tabela 4).

Foi questionado sobre o registro em prontuário, em caso de óbito de paciente terminal após decisão de não introduzir tratamento ou meca- nismo de suporte devida: $50,9 \%$ referem que documenta de forma fiel, $11,8 \%$ omitem algumas informações possivel mente relevantes por considerá-las desnecessárias, 29,2\% omitem informações por medo de problemas com o código de ética médica e/ou código penal, apenas um médico, $0,6 \%$, afirmou que documenta sua conduta no prontuário de forma inverídica e 7,5\% referem nunca ter decidido por não introduzir M SV.

Em relação às decisões que envolvem o fimda-vida de pacientes terminais, foi questionado sobre o medo de punição pelo código de ética

Tabela 2. Decisões sobre recusar a não introdução de um tratamento ou M SV.

\begin{tabular}{|c|c|c|c|}
\hline & \multicolumn{2}{|c|}{ Você participa dessa discussão? } & \multirow[b]{2}{*}{ Já optou por não introduzir MSV? } \\
\hline & $\mathrm{n}$ & $\%$ & \\
\hline Frequentemente & 111 & 68,9 & \\
\hline Pouco frequentemente & 29 & 18,0 & Sim $144(89,4)$ \\
\hline Raramente & 17 & 10,6 & Não $17(10,6)$ \\
\hline Nunca & 4 & 2,5 & \\
\hline Total & 161 & 100 & $161(100)$ \\
\hline
\end{tabular}

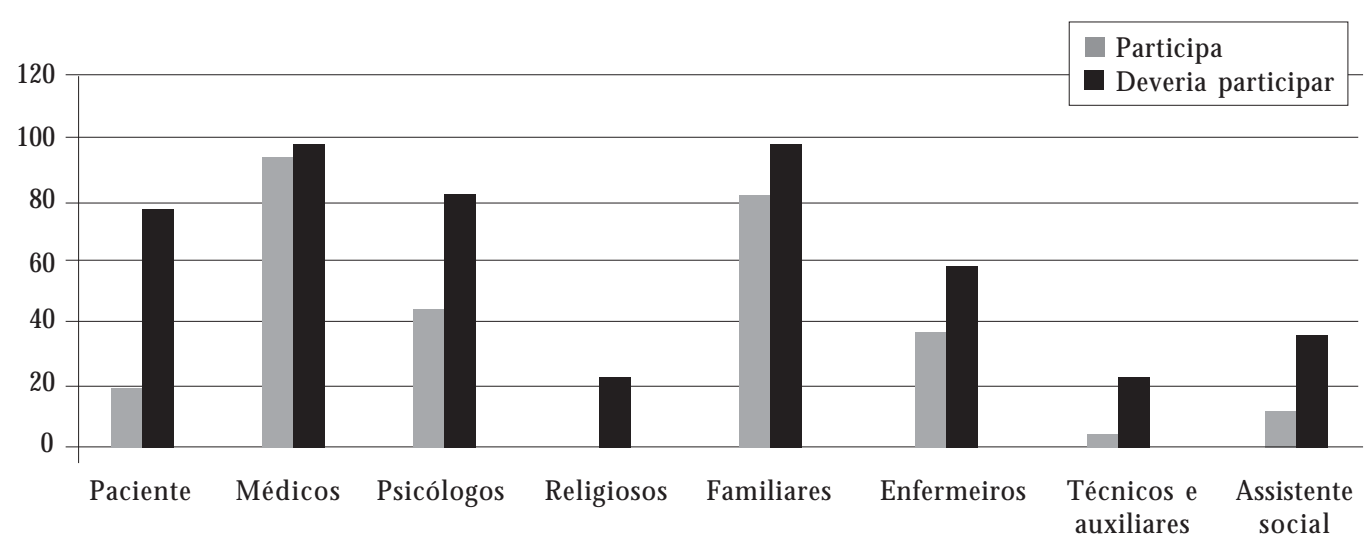

Gráfico 1. Comparação entre os participantes dos debates e quem deveria participar na opinião dos médicos.

Tabela 3. Fatores que influenciam nas decisões por odem de importância.

\begin{tabular}{lrrrrrr}
\hline \multicolumn{1}{c}{ Fatores } & 1 & 2 & 3 & 4 & 5 & Total \% \\
\hline Idade & 7,5 & 24,8 & 13,7 & 18,0 & 36,0 & 100 \\
Condições clínicas & 77,0 & 17,4 & 3,1 & 1,2 & 1,2 & 100 \\
Vontade do paciente & 19,9 & 32,3 & 26,7 & 11,8 & 9,3 & 100 \\
Opinião da família & 8,7 & 19,9 & 22,4 & 31,7 & 17,4 & 100 \\
Ética médica & 26,7 & 19,8 & 16,1 & 16,1 & 11,2 & 100 \\
\hline
\end{tabular}


médica e/ou código penal: $20,5 \%$ sempre temem algum tipo de punição, 46,0\% algumas vezes, $19,9 \%$ raramentee $13,6 \%$ nunca. A grande maioria dos médicos participantes acredita que são necessárias reformulações nesses códigos citados e $45,3 \%$ afirmam manter-se informados sobre as atualizações.

Para finalizar o questionário, um caso clínico era descrito a respeito deum pacientede 87 anos, com câncer de pulmão avançado e metástases cursando com diminuição do nível de consciência. A primeira pergunta era se o paciente sofresse uma parada cardiorrespiratória, o médico iniciaria as manobras de reanimação; $14,3 \%$ responderam que tentariam reanimá-lo. Em segui$\mathrm{da}$, era questionado se a vontade do paciente e a opinião da família influenciariam na decisão; $70,2 \%$ dos médicos afirmaram que seriam influenciados pelo paciente e $64,6 \%$, pela família. Por fim, o participante deveria imaginar que ele próprio era o paciente do caso descrito; apenas 1,9\% gostariam que as técnicas reanimatórias fossem aplicadas (Tabela 5).

Tabela 4. Perguntas 6, 7 e 8.

\begin{tabular}{lrrr}
\hline${ }^{*}$ Pergunta & \multicolumn{1}{c}{6} & \multicolumn{1}{c}{7} & \multicolumn{1}{c}{8} \\
\hline Sim & - & $108(67,1)$ & $81(50,3)$ \\
Não & $119(73,9)$ & $5(3,1)$ & $30(18,6)$ \\
Em algunscasos & $42(26,1)$ & $48(29,8)$ & $20(31,1)$ \\
Total & $161(100 \%)$ & $161(100 \%)$ & $161(100 \%)$ \\
\hline
\end{tabular}

*6- Vocêéa favor de continuar submetendo o pacientea todo tratamento etecnologia disponível, mesmo em caso de doença terminal?

7 - Vocêé a favor de interromper um tratamento em caso de paciente terminal?

8 - Vocêéa favor de retirar um M SV em caso de pacienteterminal?

\section{Discussão}

A literatura vem abordando, cada vez mais, os assuntos relacionados ao fim-da-vida e muitos estudos sobre os pacientes terminais nas unidades de terapia intensiva já foram realizados. Os médicos participantes do presente trabal ho confirmaram que discussões sobre 0 assunto ocorrem frequentemente no ambiente hospitalar.

Geralmente, o médico não decide sozinho e outros profissionais, às vezes familiares e/ou 0 próprio paciente, participam das discussões. Dentre médicos, psicólogos, religiosos, enfermeiros, técnicos, assistentes sociais, familiares e pacientes, ficou claro, na atual pesquisa, que médicos e familiares são os que mais participam dos debates. Entretanto, ficou evidenciada uma divergência entre o que acontece na prática e o que os médicos consideram como certo, sendo que a maioria respondeu que é a favor da participação, além do médico e de familiares, de psicólogos, enfermeiros e o próprio paciente, concordando com o Jonhston ${ }^{13}$, anteriormente citado, o qual mostrou que os médicos acreditavam que o próprio paciente, se apresentasse condições, deveria ajudar a decidir sobre o processo do seu fim-devida.

É notável queexisteuma tendência dos médicosque lidam com pacientes terminais a assumir condutas para fornecer conforto, deixando inclusive de introduzir um MSV que ajudaria a prolongar uma vida. A atual pesquisa confirma essa nova visão de intervenção diante de um paciente sem prognóstico, visto que a maioria dos participantes afirma já ter optado por não introduzir um MSV.

Deixar de introduzir suporte vital ou um tratamento são condutas médicas que devem ser cautelosamente analisadas e discutidas e muitos

Tabela 5. Caso clínico.

\begin{tabular}{lrrr}
\hline \multicolumn{1}{c}{ Caso * $^{*}$} & \multicolumn{1}{c}{ Sim } & Não & Não tenho certeza \\
\hline Iniciar as técnicas reanimatórias? & $23(14,3)$ & $115(71,4)$ & $23(14,3)$ \\
Vontade do paciente & $113(70,2)$ & $36(22,4)$ & $12(7,5)$ \\
Opinião da família & $104(64,6)$ & $40(24,8)$ & $17(10,6)$ \\
E se fosse você? & $3(1,9)$ & $144(89,4)$ & $14(8,7)$ \\
\hline
\end{tabular}

* Paciente87 anos com CA de pulmão avançado emetástases. Encontra-senaUTI com diminuição do nível de consciênciae apresentou parada cardiorrespiratória.

Vocêiniciaria as técnicas reanimatórias?

Sevocêfosse previamente informado sobrea vontade do paciente, sua decisão poderia ser influenciada?

Sevocêfosse previamenteinformado sobrea vontade dos familiares, sua decisão poderia ser influenciada?

Imaginequevocêéo paciente descrito acima. Vocêgostaria que as manobras reanimatórias fossem iniciadas? 
fatores influenciam na decisão. Segundo os dados obtidos através das respostas dos médicos participantes, ficou claro que as condições clínicas, ou seja, a falta de prognóstico, é o fator de maior importância para essas decisões, seguido da ética médica. A vontadedo paciente e opinião da família também influenciam com importância moderada, já a idade foi considerada, pela maioria, um fator de baixa importância para a decisão final.

A respeito da legalização da eutanásia no Brasil, a maioria écontra eum percentual deincerteza de 25,5 pode ser considerado alto, visto quese espera que médicos intensivistas tenham uma opinião formada sobre 0 assunto. Vale ressaltar que essa questão visava obter apenas opiniões, não se referindo à prática médica, uma vez quea eutanásia é uma conduta proibida no país.

Distanásia é considerada um sinônimo de obstinação terapêutica, ou seja, prática médica obstinada a prolongar a vida do paciente a despeito do prolongamento do sofrimento. Atualmente, recursos como não introduzir M SV ou até mesmo retirá-lo são possibilidades analisadas a fim de conduzir a morte do paciente de forma digna, sem prolongar ou abreviar, como enfatiza o conceito de ortotanásia. Todavia, não introduzir e retirar um M SV ainda são condutas polêmicas e podem não ser aceitas de maneira semelhante. Os dados obtidos na presente pesquisa demonstram que a maioria dos médicos intensivistas é contra insistir na terapêutica em pacientes sem prognóstico. Se $89,9 \%$ afirmam já ter optado por não introduzir M SV, 67,1 \% são a favor de interromper um tratamento já iniciado eapenas a metade dos partici pantes, $50,3 \%$, concordam com a retirada de um M SV, presume-se que essas questões são entendidas de forma distinta. Por outro lado, Dickenson ${ }^{14}$ mostrou que os médicos ingleses enorte-americanos não consideram eticamentediferentes as condutas denão introduzir e de retirar M SV.

Sendo as questões éticas acerca das condutas médicas diantede pacientes terminais um assunto atual e polêmico, é de extrema importância que aqueles que vão lidar diretamente com esse grupo de enfermos se mantenham informados. Portanto, apesar de termos como distanásia e ortotanásia não possuírem consenso na literatura bioética sobre suas definições, éimportante que os intensivistas busquem seus conceitos.

0 registro no prontuário deveria ser fidedigno à conduta realizada; entretanto, o presente trabalho demonstra que os intensivistas evitam registrar algumas condutas. A maioria dos mé dicos admitiu que omite informações no prontuário, seja por considerá-las desnecessárias, ou por receio de punição pelo código de ética e/ou penal. Além da falta de protocolos hospitalares de condutas diante de um paciente sem esperança de cura, como limitação de suporte vital, a ausência de uma legislação clara e objetiva a respeito do assunto contribui para a insegurança dos médicos.

Apesar de a maioria afirmar que teme punições e achar necessárias reformulações no código deética médicae/ou código penal, uma minoria afirmou quesemantém atualizada. Cada profissional deveria ter interesseem buscar conhecimento; todavia, as próprias instituições precisam incentivar seus funcionários a se manterem informados diante de questões éticas e jurídicas.

No caso clínico apresentado no questionário, o qual se referia a um paciente idoso eem estágio avançado de câncer de pulmão metastático, a maioria dos médicos respondeu quenão iniciaria as técnicas reanimatórias se 0 paciente evoluísse com parada cardiorrespiratória. É interessante que, quando foi pedido que os médicos se imaginassem no lugar do paciente do caso citado, o percentual de não iniciar as manobras de reanimação aumentou. Ou seja, alguns responderam que tentariam a reanimação no pacientedescrito; todavia, preferiam que essas manobras não fossem realizadas se eles fossem o paciente. A opinião do paciente e da família não foi considerada deforte importância para todos os médicos. Esse não seria um dado que demonstra a insistência de alguns profissionais em centralizar o poder decisório nos médicos, não respeitando assim os desejos individuais do moribundo?

\section{Considerações finais}

Indubitavelmente, a medicina intensiva vem passando por transformações no âmbito das suas intervenções frente ao paciente terminal. Uma nova visão de medicina crítica, a qual prioriza o conforto do enfermo, vem substituindo uma medicina obstinada a manter o paciente vivo. Essas mudanças trazem a oportunidade de pacientes sem prognóstico evoluírem com uma morte menos sofrida.

Entretanto, os médicos intensivistas se deparam com conflitos éticos e culturais os quais vão interferir na conduta final. E descentralizar 0 poder decisório, queainda seconcentranas mãos do médico, e deixar o próprio sujeito, quando possível, decidir sobre o fim da sua vida, ainda é 
um desafio. Diante de um cotidiano repleto de dilemas, percebe-se um distanciamento entre a prática médica e a opinião dos profissionais nas unidades de terapia intensiva.

0 código de ética médica atual já apresenta algumas mudanças da visão ética a respeito da prática médica diante de pacientes terminais, mostrando uma medicina preocupada em não submeter o paciente a um fim-de-vida doloroso. Todavia, este estudo mostra que há certa insegurança quanto a definições importantes que envolvem os pacientes sem prognóstico. A falta de uma legislação clara e objetiva a respeito do as-

\section{Colaboradores}

D Gaudêncio e 0 M esseder participaram igualmente de todas as etpas da elaboração do artigo.

\section{Referências}

1. Elias N. A solidão dos moribundos. Rio de Janeiro: Jorge Zahar; 2001.

2. Pessini L. Distanásia: até quando prolongar a vida? São Paulo: São Camilo-Loyola; 2001.

3. Batista SR, Schramm RF. Eutanásia: pelas veredas da morte e da autonomia. Cien Saude Colet 2004; 9(1):31-41.

4. Kipper DJ, Piva JP. Dilemas éticos e legais em pacientes criticamente doentes. J Pediatr (Rio J). 1998; 74:261-262.

5. Lang F, Quill T. Making Decisions with Families at the End of Life. American Family Physician [periódico na Internet] 2004 [acessado 2007 jan]. Disponível em: http://www.aafp.org/afp

6. Pessini L. Eutanásia: por que abreviar a vida? São Paulo: Loyola; 2004.

7. Pessini L. Distanásia: algumas reflexões bioéticas a partir da realidade brasileira. Bioética 2004; 12(1):39-60.

8. Kubler-Ross E. Sobre a morte e o morrer: o que os doentes terminais têm para ensinar a médicos, enfermeiras, religiosos e aos seus próprios parentes. São Paulo: M artins Fontes; 1998.

9. Zucker BM. Medical Futility: and the evaluation of life-sustaining interventions. Cambridge: Cambridge University Press; 1997.

10. Vincent JL. Forgoing life support in western European intensive care units: the results of an ethical questionnaire. Critical Care M edicine 1999; 27(8):16261633. sunto, bem como a falta de interesse dos próprios profissionais em se manter informados, resulta numa medicina intensiva insegura. Um sinal importante dessa insegurança é a omissão de informações no prontuário e o registro inacurado da conduta realizada.

Percebe-se, portanto, a necessidade deamplas discussões multidisciplinares sobreessas questões no ambiente hospitalar, assim como para esclarecer a sociedade a respeito desse tão importante tema. É imprescindível quenão apenas os profissionais busquem manter-se informados, mas também as próprias instituições os incentivem.

11. Lago P. Jefferson $P$, Délio $K$, Pedro CG, Cristiane $P$, Mateus G, Branco R, Bueno F, Traiber C, Araújo T, Wortmann D, Librelato $G$, Soardi D. Limitação de suporte de vida em três unidades de terapia intensiva pediátrica do sul do Brasil. J Pediatr (Rio J). 2005; 81(2):111-117.

12. Piva JP, Carvalho PRA. Considerações éticas nos cuidados médicos do paciente terminal. Bioética 1993; 1:129-138.

13. Jonhston CS, Pfeifer PM. End-of-life Study Group: patient and physician roles in end-of-life decision making. J Gen Intern M ed 1998; 13:43-45.

14. Dickenson LD. Are medical ethicists out of touch? Practitioner end of life attitudes in the US and UK towards decisions at the end of life. J. M ed. Ethics 2000; 26:254-260.

15. Cook D, Graeme R, Daren H. Dying in the ICU: strategies that may improve end-of-life care. Can J Anesth 2004; 51(3):266-272.

16. Carvalho PRA, Rocha TS, Santo AE, Lago P. Modos de Morrer na UTI Pediátrica de um Hospital Terciário. Rev. Assoc. Med. Bras. 2001; 47(4):325-331.

17. Gil AC. M étodos e técnicas de pesquisa social. $5 a$ ed. São Paulo: Atlas; 1999.

Artigo apresentado em 11/03/2008

Aprovado em 30/10/2008

Versão final apresentada em 11/12/2008 